\title{
Review of genus Pseudorthocladius Goetghebuer, 1943 (Diptera, Chironomidae) from China
}

\author{
Jing Ren ${ }^{1, \dagger}$, Xiaolong Lin ${ }^{1, \neq}$, Xinhua Wang ${ }^{1, \S}$ \\ I College of Life Sciences, Nankai University, Tianjin 300071, China \\ † http://zoobank.org/7EEFA7EF-EOFF-4DC3-962D-6D729A9DC7EE \\ † http://zoobank.org/AC3964DC-0709-4DCB-96AA-6EBEDFA04C07 \\ § http://zoobank.org/ACC3483B-5DD1-4F2D-88F7-1CE4C6458B68 \\ Corresponding author: Xinhua Wang (xhwang@nankai.edu.cn)
}

Academic editor: V. Blagoderov | Received 17 June 2013 | Accepted 9 February 2014 | Published 11 March 2014

http://zoobank.org/D52BB193-A727-47DB-82A1-019D652A3D35

Citation: Ren J, Lin X, Wang X (2014) Review of genus Pseudorthocladius Goetghebuer, 1943 (Diptera, Chironomidae) from China. ZooKeys 387: 51-72. doi: 10.3897/zookeys.387.5808

\begin{abstract}
The genus Pseudorthocladius Goetghebuer, 1943 from China, including 12 species, is reviewed. Five new species, $P$. $(P$.) binarius sp. n., $P$. (P.) cylindratus sp. n., $P$. (P.) digitus sp. n., $P$. (P.) ovatus sp. n. and $P$. $(P$.$) paucus sp. n. are described and illustrated as adult males. P$. (P.) cristagus Stur \& Sæther, 2004, $P$. (P.) jintutridecima (Sasa, 1996), P. (P.) macrovirgatus Sæther \& Sublette, 1983, P. (P.) morsei Sæther \& Sublette, 1983, P. (P.) uniserratus Sæther \& Sublette, 1983, P. (L.) wingoi Sæther \& Sublette, 1983 are newly recorded in Oriental Region. A key to the males of Pseudorthocladius in China is presented.
\end{abstract}

\section{Keywords}

Chironomidae, Pseudorthocladius, new species, new record, key, Oriental, China

\section{Introduction}

The genus Pseudorthocladius Goetghebuer, 1943 contains two subgenera, Pseudorthocladius Goetghebuer and Lordella Sæther \& Sublette (Sæther and Sublette 1983). The two subgenera are different in the shape of inferior vosella and microtrichia 
on the gonostylus. The presence of well developed pulvilli [except $P$. $(P$.) oyabecrassus Sasa, Kawai \& Ueno, 1988], an apical antennal seta, lack of pseudospurs, acrostrichals long and beginning near the antepronorum, curved $\mathrm{Cu}_{1}$ and an anal point with strong setae will separate the genus from other orthoclad genera.

The subgenus Lordella shows some similarities and possible synapomorphies with Doithrix, such as the basally widened gonostylus and hook-shaped inferior volsella. However, the long anal point and setae on the point indicating an intermediate position between typical Pseudorthocladius s. str. and Doithrix. So the status of subgenus Lordella needs to be further discussed.

The immatures of Pseudorthocladius are found in a wide variety of damp habitats including mosses, hygropetric regions, seeps and floodplains along stream banks (Strenzke 1950, Sæther and Sublette 1983, Cranston et al. 1989)

According to Ashe and O'Connor 2012, this genus presently comprises 52 valid species in the world with 34 species in the Palaearctic Region, 17 in the Nearctic Region, 5 in the Oriental Region, 2 in the Afrotropical Region. Eastern Palaearctic Asia appears to be a rich area of diversity in the genus: 24 species from Japan (Yamamoto 2004), 7 species from the Far East of Russia (Makarchenko and Makarchenko 2012), only 1 species from China (Wang 2000).

In this paper, the Pseudorthocladius based on material from China is reviewed. Five new species are described, six species are newly recorded in China, and key to the Chinese species of Pseudorthocladius is presented.

\section{Materials and methods}

The morphological nomenclature follows Sæther (1980). The materials examined are mounted on slides, following the procedure outlined by Sæther (1969). Measurements are given as ranges followed by the mean, when four or more specimens are measured, followed by the number of specimens measured (n) in parentheses. All specimens examined during this study are deposited in the College of Life Sciences, Nankai University, China.

\section{Taxonomy}

Pseudorthocladius (Pseudorthocladius) binarius sp. $\mathbf{n}$. http://zoobank.org/D5AC53EC-771A-4D91-ADF2-B3EB97CDF0FD http://species-id.net/wiki/Pseudorthocladius_binarius Figures 1-7

Diagnosis. The male imago can be distinguished from the known species of the genus by the following combination of characters: low AR (0.29); squama with few setae; anal lobe reduced; inferior volsella has two sub-lobes; virga absent. 


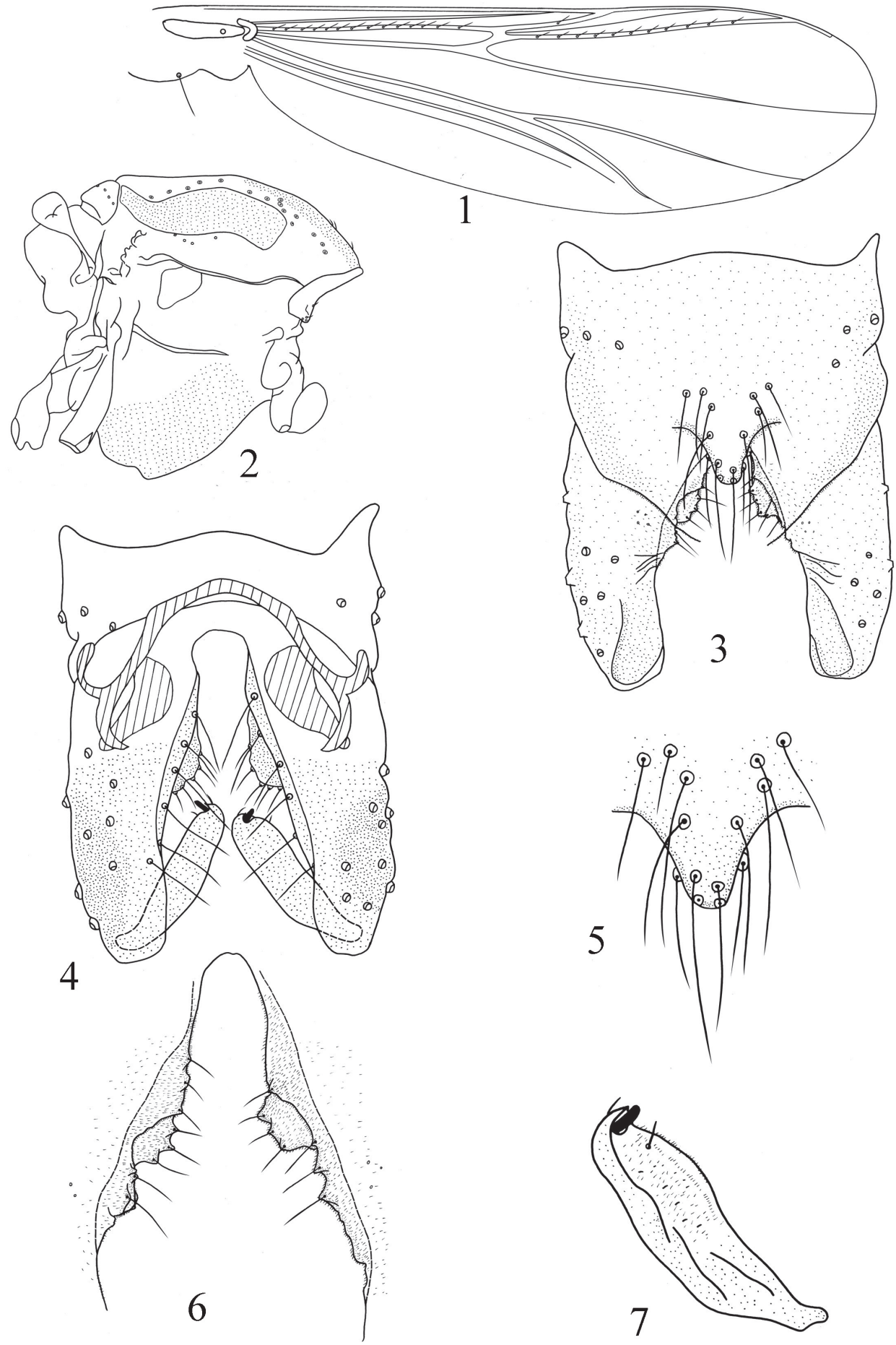

Figures I-7. Pseudorthocladius (P.) binarius sp. n., male. $\mathbf{I}$ wing $\mathbf{2}$ thorax $\mathbf{3}$ hypopygium (dorsal view) $\mathbf{4}$ hypopygium (ventral view) $\mathbf{5}$ anal point $\mathbf{6}$ inferior volsella $\mathbf{7}$ gonostylus. 
Description. Adult male $(\mathrm{n}=4)$. Total length $1.50-1.80,1.63 \mathrm{~mm}$. Wing length $0.81-0.97,0.89 \mathrm{~mm}$. Total length/wing length 1.83-1.86, 1.84. Wing length/length of profemur 2.26-2.43 (3).

Coloration. Head, abdomen, legs brown; thorax with yellow ground with brown postnotum and preepisternum.

Head. Antenna with 13 flagellomeres. Terminal flagellomere length 95-108, 105 $\mu \mathrm{m}$. AR 0.28-0.33, 0.29. Temporal setae 8 (2), including 2 (2) inner verticals, 3-4 (3) outer verticals, and 2 (2) postorbitals. Clypeus with 6-10, 8 setae. Tentorium 86-96, $92 \mu \mathrm{m}$ long, 14-19, $15 \mu \mathrm{m}$ wide. Palpomere lengths (in $\mu \mathrm{m}$ ): 19-24, 22; 26-29, 28; 55-62, 59; 84-91, 86; 98-120, 110. L: 5 ${ }^{\text {th }} 3^{\text {rd }} 1.77-2.10,1.86$.

Wing (Figure 1). VR 1.25-1.29 (3). Anal lobe reduced. Brachiolum with 1 seta; $\mathrm{R}$ with 9-15, 13 setae; $\mathrm{R}_{1}$ with $1-4,2$ setae; $\mathrm{R}_{4+5}$ 9-11, 10 setae; $M$ with $0-1,1$ seta. Squama with 1-2, 1 seta. Costal extension $70 \mu \mathrm{m}$ long. $\mathrm{Cu}_{1}$ slightly curved.

Thorax (Figure 2). Antepronotum with 3-6, 5 lateral setae, dorsocentrals 13-15, 13, acrostichals 3-7, 5, prealars 4-6, 5. Scutellum with 6-8, 7 setae.

Legs. Pulvilli present. Spur of fore tibia 29 (3) $\mu \mathrm{m}$ long, spurs of mid tibia 22-24, $23 \mu \mathrm{m}$ and 16-19, $18 \mu \mathrm{m}$ long; hind tibia with a long spur 40-43, $42 \mu \mathrm{m}$ long, a short spur $14-17,16 \mu \mathrm{m}$ long and comb composed of 10-12, 11 spines. Width at apex of fore tibia 24-28, $26 \mu \mathrm{m}$, of mid tibia 20-26, $24 \mu \mathrm{m}$, of hind tibia 31-36, $33 \mu \mathrm{m}$. Lengths (in $\mu \mathrm{m}$ ) and proportions of legs as in Table 1.

Hypopygium (Figures 3-7). Laterosternite IX with 4-6, 5 setae. Anal point (Figure 5) subtriangular with rounded apex, 24-26, $25 \mu \mathrm{m}$ long, with 13-15, 14 strong setae. Phallapodeme 22-24, $24 \mu \mathrm{m}$ long. Transverse sternapodeme 44-50, $48 \mu \mathrm{m}$ long. Virga absent. Gonocoxite 110-122, $118 \mu \mathrm{m}$ long. Inferior volsella (Figure 6) with two sub-lobes, the dorsal lobe with concave inner margin and 4-5, 5 marginal setae, the ventral lobe semi-rounded with 3-4, 3 marginal setae. Gonostylus (Figure 7) 60-67, 64 $\mu \mathrm{m}$ long, narrowed at base. Megaseta 9-10, $10 \mu \mathrm{m}$ long. HR 1.82-1.92, 1.85. HV 2.43-2.48, 2.45.

Table I. Lengths (in $\mu \mathrm{m}$ ) and proportions of legs of Pseudorthocladius (P.) binarius sp. $\mathrm{n}$.

\begin{tabular}{c|c|c|c}
\hline & $\mathbf{p}_{\mathbf{1}}$ & $\mathbf{p}_{\mathbf{2}}$ & $\mathbf{p}_{\mathbf{3}}$ \\
\hline $\mathrm{fe}$ & $350-400(3)$ & $350-400,375$ & $360-400,380$ \\
\hline $\mathrm{ti}$ & $340-420(3)$ & $350-430,373$ & $410-500,435$ \\
\hline $\mathrm{ta}_{1}$ & $250-300(2)$ & $125-150,131$ & $220-260,240$ \\
\hline $\mathrm{ta}_{2}$ & $170-210(2)$ & $72-96,78$ & $115-130,124$ \\
\hline $\mathrm{ta}_{3}$ & $120-140(2)$ & $60-72,63$ & $105-126,115$ \\
\hline $\mathrm{ta}_{4}$ & $72-84(2)$ & $36-48,42$ & $48-60,53$ \\
\hline $\mathrm{ta}_{5}$ & $51-67(2)$ & $48-50,49$ & $48-60,54$ \\
\hline $\mathrm{LR}$ & $0.71(2)$ & $0.33-0.37,0.35$ & $0.52-0.56,0.55$ \\
\hline $\mathrm{BV}$ & $2.22-2.30,2.29$ & $3.63-3.98,3.71$ & $2.98-3.13,3.02$ \\
\hline $\mathrm{SV}$ & $2.73-2.80,2.76$ & $5.53-5.72,5.62$ & $3.32-3.50,3.41$ \\
\hline $\mathrm{BR}$ & $2.50-2.60,2.56$ & $3.14-3.67,3.45$ & $3.75-4.38,4.03$ \\
\hline
\end{tabular}


Female, pupa and larva unknown.

Type materials. Holotype: $\widehat{\partial}$ (BDN No.20200), China, Fujian, Quanzhou City,

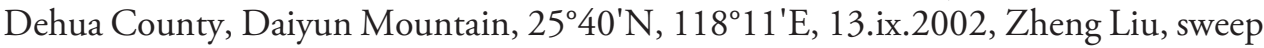
net. Paratypes: $3 \hat{\partial} \widehat{\partial}$, as holotype.

Etymology. The specific name is from Latin, binarius, meaning "of two", referring to the inferior volsella has two sub-lobes.

Remarks. The new species resembles $P$. (P.) tusimoquereus Sasa \& Suzuki (1999) in the structure of hypopygium, but can be separated from the latter on the following points: (1) $P$. (P.) binarius sp. $\mathrm{n}$. has small body size $(1.63 \mathrm{~mm})$ and low AR (0.29); (2) wing anal lobe reduced and squama with few setae; (3) inferior volsella with two sub-lobes; (4) virga absent.

Distribution. The new species is collected in a subtropical mountain area in Fujian Province (Oriental China).

\section{Pseudorthocladius (Pseudorthocladius) cristagus Stur \& Sæther, 2004} http://species-id.net/wiki/Pseudorthocladius_cristagus

Pseudorthocladius (Pseudorthocladius) cristagus Stur \& Sæther, 2004: 79; Ashe and O'Connor 2012: 531.

Diagnosis. The male imago is separable from the other species of the genus Psendorthocladius by having hairy wings, strong crista dorsalis and outer heel of the gonotylus.

Specimens examined. China, Zhejiang: 1 त (BDN No.K5B50), Taizhou

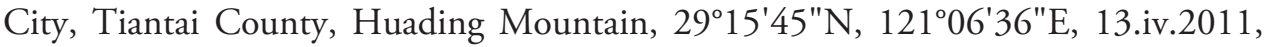
Xiaolong Lin, sweep net.

Remarks. Stur and Sæther (2004) erected a hairy-winged species $P$. (P.) cristagus based on the specimen from Luxemburg. The species can be separated from close species $P$. (P.) pilosipennis by having a gonostylus with a prominent crista dorsalis and an outer heel. The Chinese specimen mainly agrees with the original description of Stur and Sæther (2004). Some measured differences between the specimens from China and Luxemburg are shown in Table 2.

Distribution. Zhejiang Province (Oriental China); Luxemburg.

Table 2. Differences between the specimens from China and Luxemburg.

\begin{tabular}{c|c|c}
\hline & Chinese specimen & Luxemburg specimens \\
\hline $\mathrm{TL}$ & $2.48 \mathrm{~mm}$ & $3.35-3.41 \mathrm{~mm}$ \\
\hline $\mathrm{WL}$ & $1.63 \mathrm{~mm}$ & $1.89-2.02 \mathrm{~mm}$ \\
\hline $\mathrm{AR}$ & 1.05 & $1.08-1.14$ \\
\hline $\mathrm{LR}_{1}$ & 0.62 & $0.75-0.76$ \\
\hline
\end{tabular}


Pseudorthocladius (Pseudorthocladius) curtistylus (Goetghebuer, 1921)

http://species-id.net/wiki/Pseudorthocladius_curtistylus

Hydrobaenus (Psectrocladius) curtistylus Goetghebuer, 1921: 101.

Spaniotoma (Orthocladius) curtistylus (Goetghebuer); Edwards 1929: 350.

Orthocladius (Pseudorthocladius) curtistylus (Goetghebuer); Goetghebuer 1932: 93, 1940-50: 73.

Spaniotoma curtistylus (Goetghebuer); Edwards 1932: 141.

Hydrobaenus (Pseudokiefferiella) curtistylus (Goetghebuer); Laurence 1951: 165.

Pseudorthocladius curtistylus (Goetghebuer); Thienemann and Kruger 1939: 25;

Thienemann 1944: 569, 616; Coe 1950: 160; Strenzke 1950: 230; Brundin 1956:

137; Lehmann 1971: 459; Pinder 1978: 94.

Pseudorthocladius (Pseudorthocladius) curtistylus (Goetghebuer): Sæther and Sublette 1983: 69, fig. 37; Wang 2000: 639; Ashe and O'Connor 2012: 532; Makarchenko and Makarchenko 2012: 76-77.

Diagnosis. AR 0.45-0.70; dorsocentrals $15-18$; $\mathrm{R}$ with $9-13$ setae, $\mathrm{R}_{1}$ with $2-3$ setae, $\mathrm{R}_{4+5}$ with $0-14$ setae; squama with 3-4 setae; virga present. Type I with low and extending crista dorsalis, type II with crista dorsalis absent, type III with round and protruding crista dorsalis.

Specimens examined. China, Zhejiang: 3 $\widehat{\partial}$, Wenzhou City, Taishun County, $27^{\circ} 33^{\prime} \mathrm{N}, 119^{\circ} 39^{\prime} \mathrm{E}$, 1.viii.2005, Xin Qi, light trap; Tianmu Mountain, $30^{\circ} 19^{\prime} \mathrm{N}, 119^{\circ} 26^{\prime} \mathrm{E}, 23 . v i .1998$, Bingchun Ji, sweep net. Fujian: $10 \widehat{\partial}^{\lambda}$, Wuyi City, Wuyi Mountain, $27^{\circ} 45^{\prime} \mathrm{N}, 118^{\circ} 03^{\prime} \mathrm{E}$, 30.iv.1993, Xinhua Wang, sweep net.

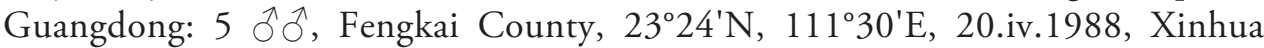
Wang, sweep net. Yunnan: $2 \hat{\jmath} \widehat{\jmath}$, Dali Bai Autonomous Prefecture, Cang Mountain, Qingbi River, 2536' N, 100 ${ }^{\circ} 15^{\prime}$ E, 23.v.1996, Yuzhou Du, light trap. Hunan: $2 \delta^{\top} \delta^{\top}$, Zhuzhou City, Yanling County, 26 $27^{\prime} \mathrm{N}, 113^{\circ} 42^{\prime} \mathrm{E}, 16 . v i i .2004$, Chuncai Yan, sweep net.

Remarks. The Chinese specimens agree with the description of $P$. (P.) curtistylus type II and type III. According to Sæther and Sublette (1983), type II without crista dorsalis, while type III with rounded and protruding crista dorsalis.

Distribution. The species is widely distributed in Holarctic region.

Pseudorthocladius (Pseudorthocladius) cylindratus sp. $\mathbf{n}$.

http://zoobank.org/399C86DD-F23B-4C2B-9E9F-E8711959DCA2

http://species-id.net/wiki/Pseudorthocladius_cylindratus

Figures $8-13$

Diagnosis. The male imago can be distinguished from the known species of the genus by the following combination of characters: cylindrical anal point; well-developed triangular inferior volsella; low AR (0.66) and high VR (1.37). 

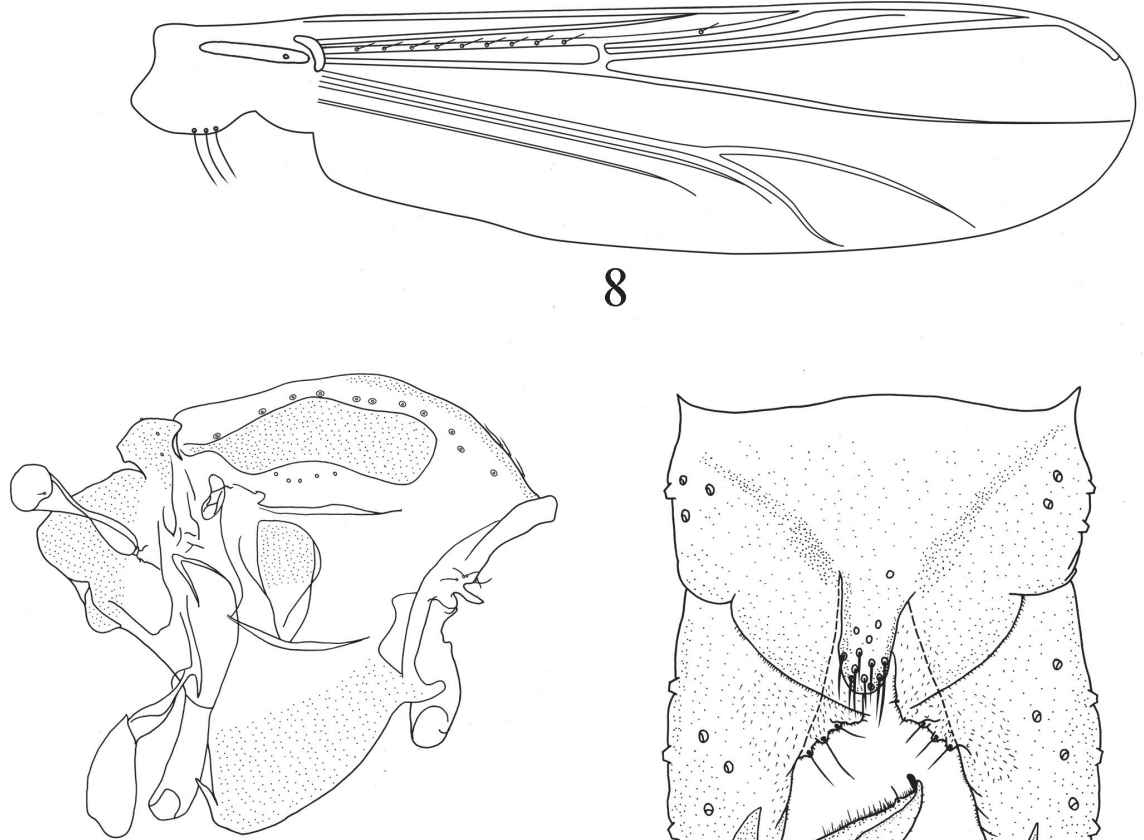

9

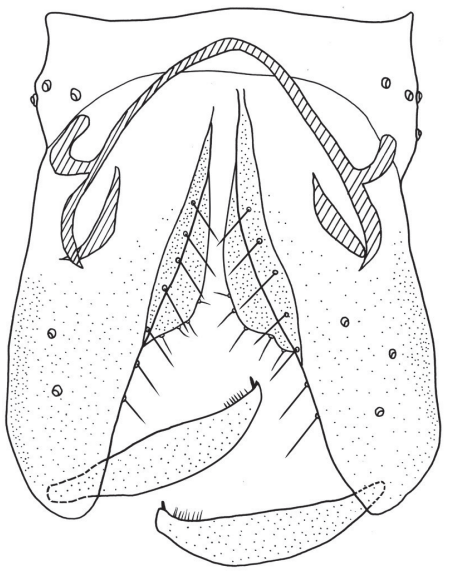

11
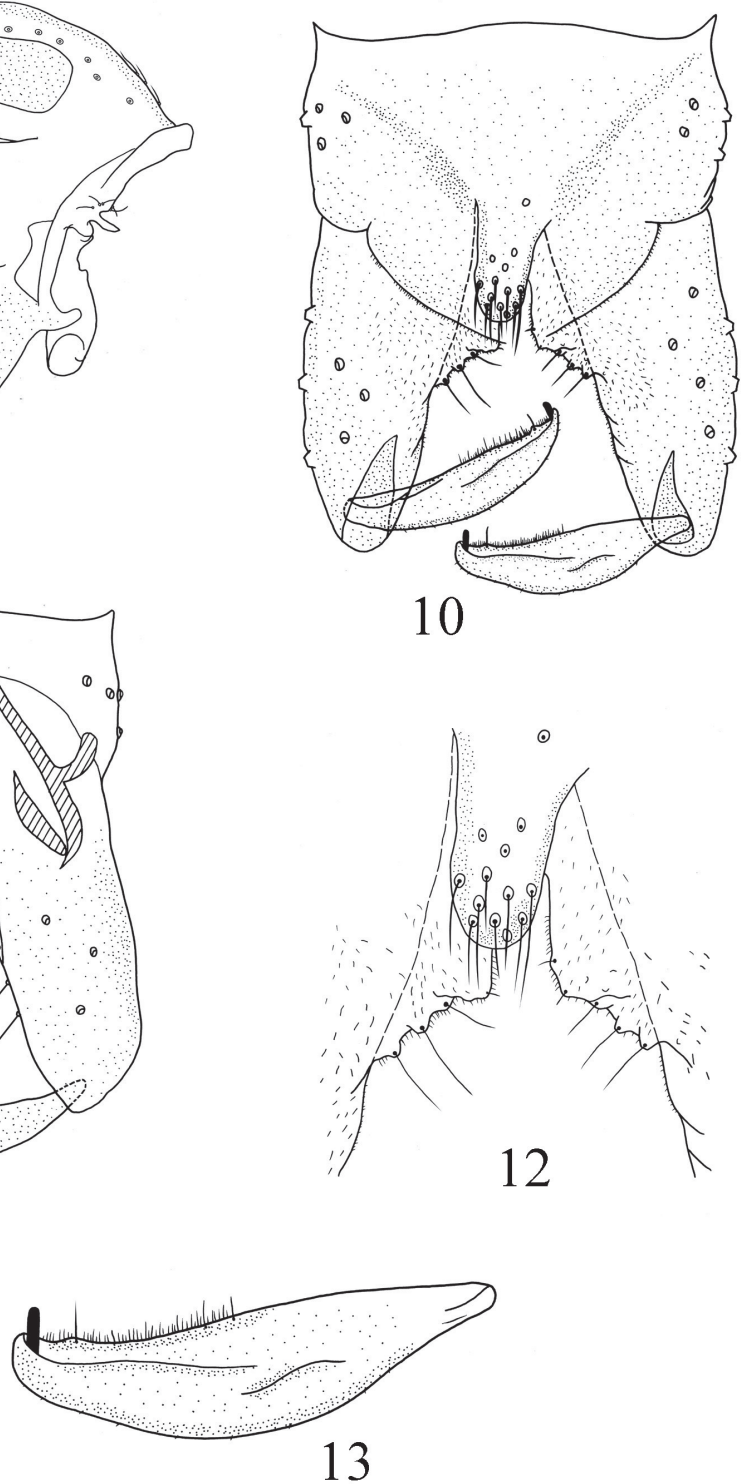

Figures 8-13. Pseudorthocladius (P.) cylindratus sp. n., male. 8 wing $\mathbf{9}$ thorax $\mathbf{1 0}$ hypopygium (dorsal view) I I hypopygium (ventral view) $\mathbf{I} \mathbf{2}$ anal point and inferior volsella $\mathbf{I} \mathbf{3}$ gonostylus. 
Description. Adult male $(\mathrm{n}=6)$. Total length $1.68-1.97,1.87 \mathrm{~mm}$. Wing length 1.04-1.19, $1.15 \mathrm{~mm}$. Total length/wing length 1.53-1.75, 1.63. Wing length/length of profemur 2.64-2.88, 2.71 .

Coloration. Head, abdomen, legs light brown; thorax with light brown ground with brownish black postnotum and preepisternum.

Head. Antenna with 13 flagellomeres. Terminal flagellomere length 235-264, 254 $\mu \mathrm{m}$. AR 0.65-0.67, 0.66. Temporal setae 8-10, 9, including 3-6, 4 inner verticals, 4-5, 5 outer verticals, and $0-2,1$ postorbital. Clypeus with 8-11, 10 setae. Tentorium 96-113, $103 \mu \mathrm{m}$ long, 18-21, $19 \mu \mathrm{m}$ wide. Palpomere lengths (in $\mu \mathrm{m}$ ): 22-26, 24; 24-28, 26; 60-72, 65; 84-91, 86; 113-137, 130. L: $5^{\text {th }} / 3^{\text {rd }} 1.87-2.28,2.00$.

Wing (Figure 8). VR 1.33-1.43, 1.37. Anal lobe obtuse. Brachiolum with 1 seta; $\mathrm{R}$ with 5-13, 9 setae; $\mathrm{R}_{1}$ with 1-4, 2 setae; other veins bare. Squama with 1-3, 2 setae. Costal extension 80-84, $81 \mu \mathrm{m}$ long. $\mathrm{Cu}_{1}$ slightly curved.

Thorax (Figure 9). Antepronotum with 4-6, 5 lateral setae, dorsocentrals 9-13, 11, acrostichals 3-7, 5, prealars 3-5, 4. Scutellum with 4-5, 5 setae.

Legs. Pulvilli present. Spur of fore tibia 29-41, $34 \mu \mathrm{m}$ long, spurs of mid tibia 19-29, $22 \mu \mathrm{m}$ and $19 \mu \mathrm{m}$ long; hind tibia with a long spur 36-41, $38 \mu \mathrm{m}$ long, a short spur 24-31, $27 \mu \mathrm{m}$ long and comb composed of 10-12, 11 spines. Width at apex of fore tibia 34-46, $37 \mu \mathrm{m}$, of mid tibia 29-31, $30 \mu \mathrm{m}$, of hind tibia 31-36, $33 \mu \mathrm{m}$. Lengths (in $\mu \mathrm{m}$ ) and proportions of legs as in Table 3.

Hypopygium (Figures 10-13). Laterosternite IX with 4-6, 5 setae. Anal point (Figure 12) cylindrical and 45-49, $48 \mu \mathrm{m}$ long and with 10-13, 11 stout setae, 2328, $25 \mu \mathrm{m}$ long. Phallapodeme 31-36, $34 \mu \mathrm{m}$ long. Transverse sternapodeme 65-67, $66 \mu \mathrm{m}$ long and convex in the middle. Virga absent. Gonocoxite 117-137, $123 \mu \mathrm{m}$ long, with 7 setae along inner margin. Inferior volsella (Figure 12) developed and triangular with 3-4, 3 strong marginal setae. Gonostylus (Figure 13) 65-72, $67 \mu \mathrm{m}$ long, narrowed at base and distal end, widen in the middle. Megaseta 8-10, $9 \mu \mathrm{m}$ long. HR 1.83-1.90, 1.85. HV 2.74-3.14, 2.78.

Female, pupa and larva unknown.

Table 3. Lengths (in $\mu \mathrm{m}$ ) and proportions of legs of Pseudorthocladius (P.) cylindratus sp. $\mathrm{n}$.

\begin{tabular}{c|c|c|c}
\hline & $\mathbf{p}_{\mathbf{1}}$ & $\mathbf{p}_{\mathbf{2}}$ & $\mathbf{p}_{\mathbf{3}}$ \\
\hline $\mathrm{fe}$ & $400-450,423$ & $440-500,466$ & $430-490,456$ \\
\hline $\mathrm{ti}$ & $340-380,360$ & $440-510,477$ & $520-570,530$ \\
\hline $\mathrm{ta}_{1}$ & $420-460,437$ & $200-220,210$ & $310-340,323$ \\
\hline $\mathrm{ta}_{2}$ & $264-280,271$ & $150-175,163$ & $156-180,171$ \\
\hline $\mathrm{ta}_{3}$ & $180-190,183$ & $142-178,152$ & $140-144,142$ \\
\hline $\mathrm{ta}_{4}$ & $98-101,100$ & $52-72,68$ & $67-74,72$ \\
\hline $\mathrm{ta}_{5}$ & $67-72,69$ & $48-55,51$ & $45-55,52$ \\
\hline $\mathrm{LR}$ & $1.11-1.23,1.19$ & $0.46-0.59,0.50$ & $0.60-0.62,0.61$ \\
\hline $\mathrm{BV}$ & $1.64-1.90,1.86$ & $2.86-3.80,2.89$ & $2.92-3.04,2.95$ \\
\hline $\mathrm{SV}$ & $1.74-1.80,1.76$ & $4.03-4.45,4.28$ & $3.00-3.05,3.02$ \\
\hline $\mathrm{BR}$ & $1.83-2.00,1.92$ & $2.86-2.92,2.88$ & $3.00-3.57,3.26$ \\
\hline
\end{tabular}


Table 4. Main differences between $P$. (P.) cylindratus sp. n. and $P$. (P.) amplicaudus Sæther \& Sublette (1983).

\begin{tabular}{c|c|c}
\hline Characters & P. (P.) cylindratus sp. n. & P. (P.) amplicaudus Sæther \& Sublette \\
\hline Anal point & $45-49 \mu \mathrm{m}$ long and cylindrical & $41 \mu \mathrm{m}$ long and widen at base \\
\hline AR & $0.65-0.67$ & 1.26 \\
\hline VR & $1.33-1.43$ & 1.14 \\
\hline $\mathrm{LR}_{1}$ & $1.11-1.23$ & 0.66 \\
\hline
\end{tabular}

Type materials. Holotype: $\widehat{\jmath}$ (BDN No.26348), China: Hunan Province, Chenzhou City, Yizhang County, Mang Mountain, 2524' N, 113²18'E, 22.vii.2004, Chuncai Yan, light trap. Paratypes (5 $\widehat{\partial}): 4 \hat{\jmath} \widehat{\jmath}$, as holotype; $1 \hat{\partial}$, Hainan Province, Changjiang County, Bawang Mountain, $19^{\circ} 15^{\prime} 36^{\prime \prime N}, 109^{\circ} 03^{\prime} 18^{\prime \prime E}$ 10.v.1988, Xinhua Wang, sweep net.

Etymology. The specific name is from Latin, cylindratus, meaning "in the form of a cylinder", referring to the cylindrical anal point, which is unique in the genus.

Remarks. The new species resembles P. (P.) amplicaudus Sæther \& Sublette, 1983 in the structure of hypopygium, but the new species can be separated from latter on the basis of main characters in Table 4.

Distribution. The new species is known from Hunan, Hainan Province in Oriental China.

\section{Pseudorthocladius (Pseudorthocladius) digitus sp. n.}

http://zoobank.org/F4701FCB-7F55-481D-8F07-0C64CF7C65BC

http://species-id.net/wiki/Pseudorthocladius_digitus

Figures 14-18

Diagnosis. The male imago can be distinguished from the known species of the genus by the following combination of characters: anal point rounded and reaching beyond the caudal margin of Tergite IX; inferior volsella finger-shaped; squama bare; anal lobe reduced.

Description. Adult male $(\mathrm{n}=1)$. Total length $2.43 \mathrm{~mm}$. Wing length $1.55 \mathrm{~mm}$. Total length/wing length 1.57. Wing length/length of profemur 2.54 .

Coloration. Head, abdomen, legs brown; thorax with yellow ground with brown postnotum and preepisternum.

Head. Antenna with 13 flagellomeres. Terminal flagellomere length $300 \mu \mathrm{m}$. AR 0.74 . Temporal setae 7, including 4 inner verticals, 3 outer verticals. Clypeus with 2 setae. Tentorium $110 \mu \mathrm{m}$ long, $24 \mu \mathrm{m}$ wide. Palpomere lengths (in $\mu \mathrm{m}$ ): 29, 31, 60, 108, -.

Wing (Figure 14). Anal lobe reduced. Brachiolum with 1 seta; $R$ with 7 setae; $R_{1}$ with 1 seta; other veins bare. Squama bare. Costa extention $41 \mu \mathrm{m}$ long. $\mathrm{Cu}_{1}$ slightly curved.

Thorax (Figure 15). Antepronotum with 5 lateral setae, dorsocentrals 7 , acrostichals 2, prealars 5. Scutellum with 9 setae.

Legs. Pulvilli present. Spur of fore tibia $50 \mu \mathrm{m}$ long, spurs of mid tibia both 29 $\mu \mathrm{m}$ long; hind tibia with a long spur $60 \mu \mathrm{m}$ long, a short spur $29 \mu \mathrm{m}$ long and comb 


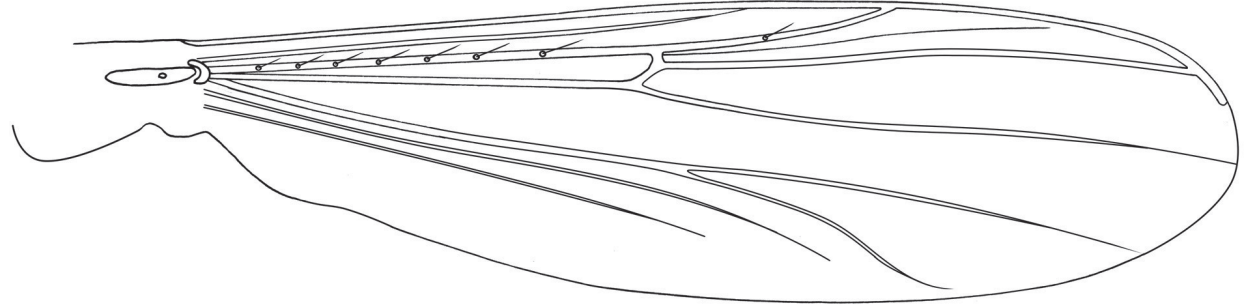

14

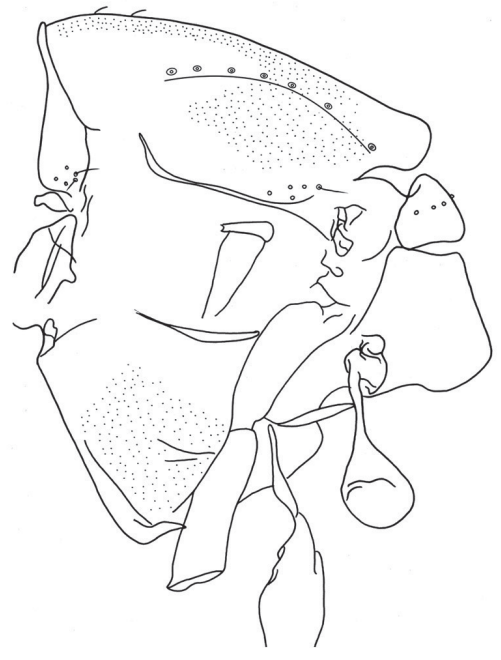

15

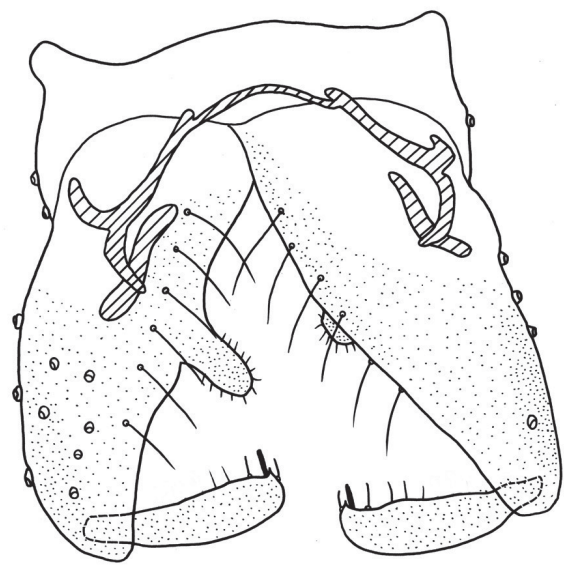

17
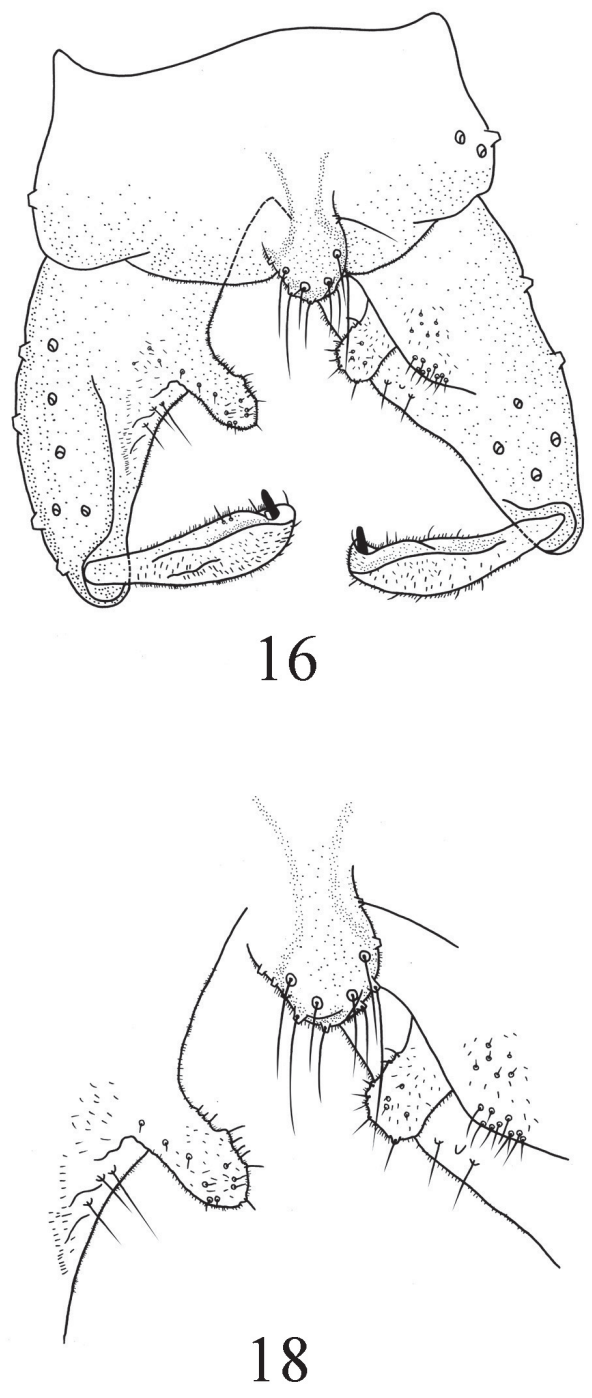

Figures 14-18. Pseudorthocladius (P.) digitus sp. n., male. $\mathbf{1 4}$ wing $\mathbf{1 5}$ thorax $\mathbf{1 6}$ hypopygium (dorsal view) $\mathbf{1 7}$ hypopygium (ventral view) $\mathbf{8}$ anal point and inferior volsella. 
Table 5. Lengths (in $\mu \mathrm{m}$ ) and proportions of legs of Pseudorthocladius (P.) digitus sp. $\mathrm{n}$.

\begin{tabular}{c|c|c|c}
\hline & $\mathbf{p}_{\mathbf{1}}$ & $\mathbf{p}_{\mathbf{2}}$ & $\mathbf{p}_{\mathbf{3}}$ \\
\hline $\mathrm{fe}$ & 610 & 660 & 700 \\
\hline $\mathrm{ti}$ & 650 & 660 & 800 \\
\hline $\mathrm{ta}_{1}$ & 410 & 264 & 450 \\
\hline $\mathrm{ta}_{2}$ & 250 & 146 & 240 \\
\hline $\mathrm{ta}_{3}$ & 156 & 101 & 180 \\
\hline $\mathrm{ta}_{4}$ & 96 & 67 & 74 \\
\hline $\mathrm{ta}_{5}$ & 72 & 60 & 72 \\
\hline $\mathrm{LR}$ & 0.63 & 0.25 & 0.56 \\
\hline $\mathrm{BV}$ & 2.91 & 4.23 & 3.44 \\
\hline $\mathrm{SV}$ & 3.07 & 5.00 & 2.33 \\
\hline $\mathrm{BR}$ & 2.63 & 1.36 &
\end{tabular}

composed of 12 spines. Width at apex of fore tibia $43 \mu \mathrm{m}$, of mid tibia $36 \mu \mathrm{m}$, of hind tibia $45 \mu \mathrm{m}$. Lengths (in $\mu \mathrm{m}$ ) and proportions of legs as in Table 5.

Hypopygium (Figures 16-18). Laterosternite IX with 3 setae. Anal point (Figure 18) rounded and reaching beyond caudal margin of Tergite IX, maximum width $22 \mu \mathrm{m}$, with 10 long marginal setae. Phallapodeme $48 \mu \mathrm{m}$ long. Transverse sternapodeme $50 \mu \mathrm{m}$ long with small oral projection. Virga absent. Gonocoxite $178 \mu \mathrm{m}$ long with 6 strong setae along inner margin. Inferior volsella (Figure 18) finger-shaped, parallel-sided and rounded in the apex, bearing some weak setae along the margin and covered by microtrichia. Gonostylus $84 \mu \mathrm{m}$ long, narrow at base, widen to the distal, with 3-4 setae along inner margin. Crista dorsalis visible, relatively low. Megaseta $10 \mu \mathrm{m}$ long. HR 2.11. HV 2.89.

Female, pupa and larva unknown.

Type materials. Holotype: $\widehat{\jmath}$ (BDN No.05327), China: Fujian Province, Wuyi City, Wuyi Mountain, 2745'N, 11803'E, 26.iv.1993, Xinhua Wang, sweep net.

Etymology. The specific name is from Latin, digitus, meaning "finger", referring to the finger-shaped inferior volsella.

Remarks. P. (P.) digitus sp.n. is close to P. (P.) yakuxeyeus (Sasa \& Suzuki, 2000) in the antenna ratio $(0.71-0.74)$ and finger-liked inferior volsella. But it can be separated from the latter by having rounded anal point reaching beyond the caudal margin of tergite IX, reduced wing anal lobe and bare squama.

Distribution. The new species is known from Fujian Province in Oriental China.

\section{Pseudorthocladius (Pseudorthocladius) jintutridecima (Sasa, 1996)}

http://species-id.net/wiki/Pseudorthocladius_jintutridecima

Eukiefferiella jintutridecimus Sasa, 1996: 64.

? Psectrocladius (Mesopsectrocladius) jintutridecima Sæther, Ashe \& Murray, 2000: 171. Pseudorthocladius (Pseudorthocladius) jintutridecima Yamamoto 2004: 82; Ashe and O'Connor 2012: 534. 
Diagnosis. AR 0.25-0.96; wing anal lobe near rectangular; tergite IX without anal point, just with a strongly chitinized broad and rounded ridge, bearing 13 strong setae; inferior volsella low and round, posterior corner.

Specimens examined. China, Sichuan: 1 đ , Baoxing County, 30²4'N, $102^{\circ} 54^{\prime} \mathrm{E}$, 19.vi.1996, Ruilei Zhang, light trap. Shaanxi: $1 \delta^{\top}$, Liuba County, 3339' N, 106 $57^{\prime} \mathrm{E}$,

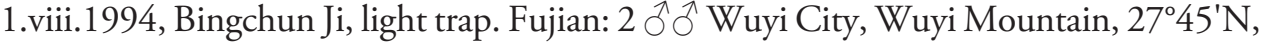

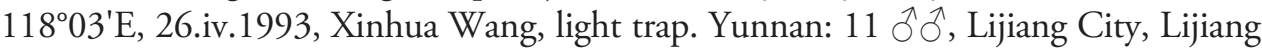
County, Shigu town, Chongjiang river, 2651'N, 100¹4'E, 25.v.1996, Xinhua Wang,

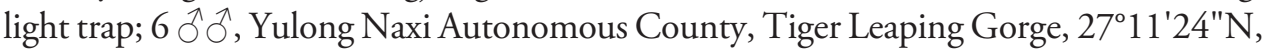
$100^{\circ} 07^{\prime} 12^{\prime} E$, 26.v.1996, Xinhua Wang, light trap. Guangdong: 1 đ̃, Fengkai County, $23^{\circ} 24^{\prime} \mathrm{N}, 111^{\circ} 30^{\prime} \mathrm{E}, 20 . i v .1988$, Xinhua Wang, sweep net.

Remarks. Sasa (1996) described this species based on the material from Japan, and put it in the genus Eukiefferiella. Sæther, Ashe and Murray (2000) transferred this species to the genus? Psectrocladius. Yamamoto (2004) transferred it into the genus Pseudorthocladius. The Chinese specimens agree with the original description of Sasa (1996) with exception of Chinese specimens have lower AR (0.25-0.86).

Distribution. Shaanxi, Fujian, Guangdong, Sichuan, Yunnan Province (Oriental China); Japan.

\section{Pseudorthocladius (Pseudorthocladius) macrovirgatus Sæther \& Sublette, 1983}

http://species-id.net/wiki/Pseudorthocladius_macrovirgatus

Pseudorthocladius (Pseudorthocladius) macrovirgatus Sæther \& Sublette, 1983: 88; Ashe and O'Connor 2012: 535.

Pseudorthocladius (Pseudorthocladius) cranstoni Sæther \& Sublette, 1983: 92; Schnell Ø. A. 1991: 5-10.

Diagnosis. AR 1.04-1.18; $\mathrm{R}_{4+5}$ with $0-8$ setae, squama with 6-15 setae; virga consisting of 2 broad lateral spines and 4 partially fused median spines, about $0.5 \times$ as long as gonostylus; gonostylus well-developed with rounded inferior volsella.

Specimens examined. China, Zhejiang: 1 ๙ , Taizhou City, Tiantai County, Baxian Lake, 2909' N, 12057'E, 13.iv.2011, Xiaolong Lin, sweep net.

Remarks. The Chinese specimen mainly agrees with the original description by Sæther and Sublette (1983). Some measured differences between the Chinese

Table 6. Differences between the specimens of China and description of Sæther and Sublette (1983).

\begin{tabular}{c|c|c}
\hline & Chinese specimen & Description of Sæther \& Sublette \\
\hline $\mathrm{TL}$ & $2.58 \mathrm{~mm}$ & $2.46-2.47 \mathrm{~mm}$ \\
\hline $\mathrm{WL}$ & $1.50 \mathrm{~mm}$ & $1.07-1.37 \mathrm{~mm}$ \\
\hline $\mathrm{VR}$ & 1.08 & $1.15-1.21$ \\
\hline $\mathrm{LR}_{1}$ & 0.62 & $0.57-0.62$ \\
\hline $\mathrm{HV}$ & 2.68 & $3.57-3.61$ \\
\hline
\end{tabular}


specimen and the specimen described by Sæther and Sublette (1983) are shown in Table 6.

Distribution. Zhejiang Province (Oriental China); Europe (Norway; Great Britain; Ireland; France and Netherlands, and North America (U.S.A. and Canada).

Pseudorthocladius (Pseudorthocladius) morsei Sæther \& Sublette, 1983 http://species-id.net/wiki/Pseudorthocladius_morsei

Pseudorthocladius (Pseudorthocladius) morsei Sæther \& Sublette, 1983: 85; Ashe and O'Connor 2012: 535.

Diagnosis. AR 0.78-0.97; virga consisting of tight cluster of about 10 spines and 2 broader lateral blades; inferior volsella with concave inner margin and 1 anterior and 1 posterior corner; gonostylus with basal inner lobe, a sharp bend distad of the middle, and a narrow apical posterior.

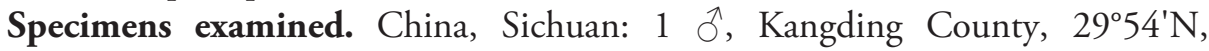
$102^{\circ} 06^{\prime} \mathrm{E}, 8 . v i .1996$, Xinhua Wang, light trap.

Remarks. Sxther and Sublette (1983) described $P$. (P.) morsei based on the material from U.S.A. Its gonostylus has a basal inner lobe, sharply bend distad of the middle and narrow in apical posterior, which is unique among Pseudorthocladius. The Chinese specimen agrees with the description except some minor differences shown in Table 7.

Distribution. Sichuan Province (Oriental China); U.S.A.; Canada.

Table 7. Differences between the specimen of China and description of Sæther and Sublette (1983).

\begin{tabular}{c|c|c}
\hline & Chinese specimen & Description of Sæather \& Sublette \\
\hline TL & $2.53 \mathrm{~mm}$ & $1.97 \mathrm{~mm}$ \\
\hline $\mathrm{WL}$ & $1.80 \mathrm{~mm}$ & $1.19 \mathrm{~mm}$ \\
\hline $\mathrm{AR}$ & 0.97 & 0.78 \\
\hline $\mathrm{VR}$ & 1.12 & 1.09 \\
\hline $\mathrm{LR}_{1}$ & 0.62 & 0.59 \\
\hline Virga & $\begin{array}{c}\text { consisting of tight cluster of about 8 } \\
\text { spines and 2 thin lateral spines }\end{array}$ & $\begin{array}{c}\text { consisting of tight cluster of about 10 } \\
\text { spines and 2 broader lateral blades }\end{array}$ \\
\hline inferior vollsella & rectangular without visible corner & \begin{tabular}{l} 
with obvious anterior and posterior corner \\
\hline
\end{tabular}
\end{tabular}

Pseudorthocladius (Pseudorthocladius) ovatus sp. $\mathbf{n}$.

http://zoobank.org/672C06D7-0A63-4040-BE31-188FCA2FEB77

http://species-id.net/wiki/Pseudorthocladius_ovatus

Figures 19-23

Diagnosis. The male imago can be distinguished from the known species of the genus by the following combination of characters: anal point round baring 9 long and strong setae; inferior volsella oval with round margin and bearing 8 long and stout marginal setae; high $\mathrm{AR}(1.40)$. 


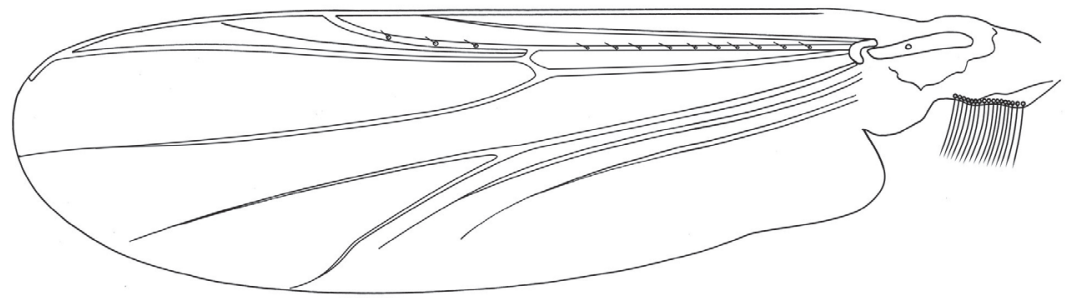

19
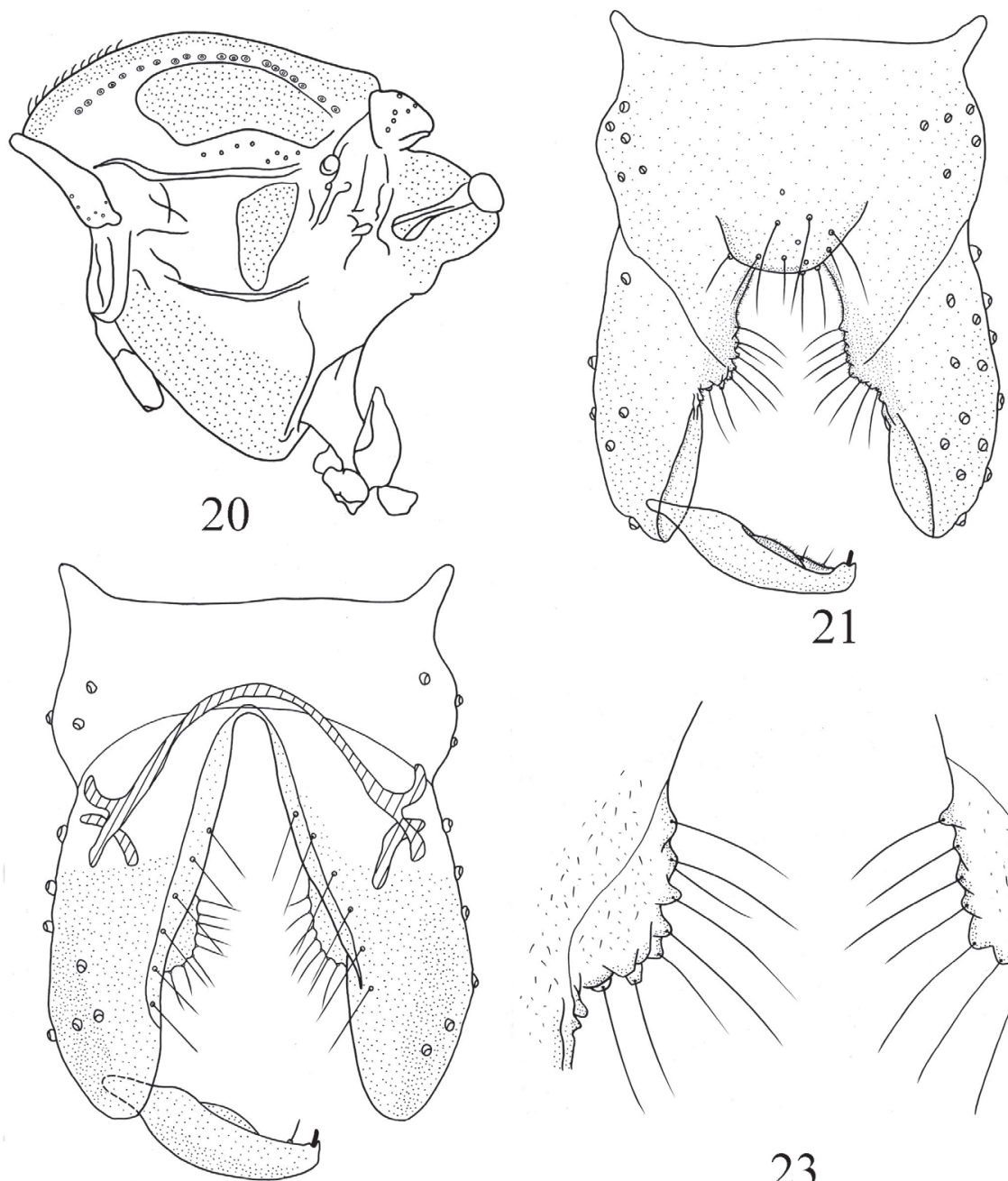

22

Figures 19-23. Pseudorthocladius (P.) ovatus sp. n., male. $\mathbf{1 9}$ wing $\mathbf{2 0}$ thorax $\mathbf{2} \mathbf{I}$ hypopygium (dorsal view) $\mathbf{2 2}$ hypopygium (ventral view) $\mathbf{2 3}$ inferior volsella. 
Description. Adult male $(\mathrm{n}=5)$. Total length $2.90-3.20,2.98 \mathrm{~mm}$. Wing length $1.43-1.55,1.47 \mathrm{~mm}$. Total length/wing length $1.88-2.08,2.00$. Wing length/length of profemur 2.26-2.41, 2.35.

Coloration. Head, abdomen, legs brown; thorax with yellow ground with brown preepisternum and brownish black postnotum.

Head. Antenna with 13 flagellomeres. Terminal flagellomere length 410-460, $440 \mu \mathrm{m}$. AR 1.31-1.55, 1.40. Temporal setae 8-11, 10, including 3-7, 4 inner verticals, 5-6, 5 outer verticals, and $0-1,1$ postorbital. Clypeus with $8-12,10$ setae. Tentorium 120-132, $126 \mu \mathrm{m}$ long, 31-33, $32 \mu \mathrm{m}$ wide. Palpomere lengths (in $\mu \mathrm{m}$ ): 31-36, $32 ; 43-45,44 ; 105-108,107 ; 155-158,156 ; 201-207,204$. L: $5^{\text {th }} / 3^{\text {rd }} 1.81-1.96,1.91$.

Wing (Figure 19). VR 1.19-1.26, 1.21. Anal lobe well-developed. Brachiolum with 1 seta; $\mathrm{R}$ with $10-12$, 10 setae; $\mathrm{R}_{1}$ with 3-4, 3 setae; other veins bare. Squama 14-18, 16 setae. Costa extension 36-50, $46 \mu \mathrm{m}$ long. $\mathrm{Cu}_{1}$ slightly curved.

Thorax (Figure 20). Antepronotum with 5-8, 6 lateral setae, dorsocentrals 20-25, 22 , acrostichals $8-12,10$, prealars $7-8,8$. Scutellum with $12-17,15$ setae.

Legs. Pulvilli present. Spur of fore tibia $45-48,46 \mu \mathrm{m}$ long, spurs of mid tibia both 19-24, $22 \mu \mathrm{m}$ long; hind tibia with a long spur 48-52, $50 \mu \mathrm{m}$ long, a short spur 17-24, $22 \mu \mathrm{m}$ long and comb composed of 12-14, 13 spines. Width at apex of fore tibia $38-43,41 \mu \mathrm{m}$, of mid tibia $31-40,36 \mu \mathrm{m}$, of hind tibia $43-48,45 \mu \mathrm{m}$. Lengths (in $\mu \mathrm{m}$ ) and proportions of legs as in Table 8.

Hypopygium (Figures 21-23). Laterosternite IX with 6-7, 6 setae. Tergite IX with round anal point, bearing 9-10, 9 long and strong setae. Phallapodeme 36-40, $38 \mu \mathrm{m}$ long. Transverse sternapodeme 72-84, $81 \mu \mathrm{m}$ long. Virga absent. Gonocoxite 153-168, $162 \mu \mathrm{m}$ long with oval inferior volsella (Figure 23) with rounded margin and bearing 8 long, stout marginal setae. Gonostylus 89-96, $98 \mu \mathrm{m}$ long, with small crista dorsalis. Megaseta 5-7, $6 \mu \mathrm{m}$ long. HR 1.70-1.89, 1.75. HV 3.18-3.23, 3.22.

Female, pupa and larva unknown.

Type materials. Holotype: $\delta$ (BDN No.26746), China: Zhejiang Province, Wenzhou City, Taishun County, 27³3'N, 119³9'E, 1.viii.2005, Bingchun Ji, light trap.

Table 8. Lengths (in $\mu \mathrm{m}$ ) and proportions of legs of Pseudorthocladius (P.) ovatus sp. n.

\begin{tabular}{c|c|c|c}
\hline & $\mathbf{p}_{\mathbf{1}}$ & $\mathbf{p}_{\mathbf{2}}$ & $\mathbf{p}_{\mathbf{3}}$ \\
\hline $\mathrm{fe}$ & $600-650,630$ & $640-700,670$ & $650-700,678$ \\
\hline $\mathrm{ti}$ & $720-800,750$ & $620-670,648$ & $760-850,825$ \\
\hline $\mathrm{ta}_{1}$ & $480-550(4), 498$ & $250-330,280$ & $400-500,562$ \\
\hline $\mathrm{ta}_{2}$ & $310-340(4), 320$ & $122-156,148$ & $240-260,250$ \\
\hline $\mathrm{ta}_{3}$ & $210-250(4), 230$ & $100-115,110$ & $161-210,192$ \\
\hline $\mathrm{ta}_{4}$ & $140-150(4), 143$ & $60-72,66$ & $96-110,102$ \\
\hline $\mathrm{ta}_{5}$ & $90-100(4), 96$ & $60-72,66$ & $79-90,87$ \\
\hline $\mathrm{LR}$ & $0.67-0.69(4), 0.68$ & $0.41-0.46,0.43$ & $0.53-0.59,0.56$ \\
\hline $\mathrm{BV}$ & $2.37-2.76(4), 2.41$ & $4.04-4.25,4.17$ & $2.70-3.22,3.11$ \\
\hline $\mathrm{SV}$ & $2.52-2.69(4), 2.59$ & $4.24-4.37,4.32$ & $3.08-3.27,3.19$ \\
\hline $\mathrm{BR}$ & $1.67-2.22(4), 1.88$ & $2.65-2.78,2.70$ & $2.27-2.69,2.54$ \\
\hline
\end{tabular}


Table 9. Main differences between $P$. (P.) ovatus sp. n. and P. (P.) matusecundus Sasa and Kawai (1987).

\begin{tabular}{c|c|c}
\hline & P. (P.) ovatus sp. n. & P. (P.) matusecundus Sasa \& Kawai \\
\hline AR & $1.31-1.55$ & 1.09 \\
\hline palp segment & 5 & 4 \\
\hline inferior volsella & oval with round margin & small with round margin and a small posterior corner \\
\hline gonostulus & widest at about basal $1 / 3$ & widest at about distal $1 / 3$. \\
\hline
\end{tabular}

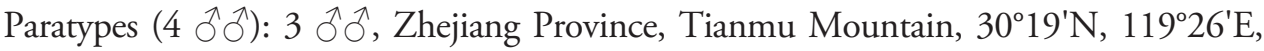
8.ix.1998, Xinhua Wang, light trap; $1 \hat{\jmath}$, Zhejiang Province, Lishui City, Qingyuan county, $27^{\circ} 39^{\prime} \mathrm{N}, 119^{\circ} 09^{\prime} \mathrm{E}, 13$.vii.1994, Hong Wu, sweep net.

Etymology. The specific name is from Latin, ovatus, meaning egg-shaped, referring to the oval inferior volsella.

Remarks. The new species is close to $P$. (P.) matusecundus Sasa \& Kawai, 1987 in the structure of hypopygium, but can be separated from the latter on the basis of characters in Table 9.

Distribution. The new species is known from Zhejiang Province in Oriental China.

\section{Pseudorthocladius (Pseudorthocladius) paucus sp. n.}

http://zoobank.org/1BEF00CA-4362-49BE-85D9-E161C9E2BDD0

http://species-id.net/wiki/Pseudorthocladius_paucus

Figures 24-30

Diagnosis. The male imago can be distinguished from the known species of the genus by the following combination of characters: with few setae on squama, $\mathrm{R}_{4+5}$ and acrostichals; gonostylus expanded at the apex; anal point triangular baring about 7 stout setae; inferior volsella inserted along the gonocoxite, parallel-sided.

Description. Adult male $(\mathrm{n}=3)$. Total length $1.49-1.60 \mathrm{~mm}$. Wing length $0.77-0.92$ $\mathrm{mm}$. Total length/wing length 1.74-1.75. Wing length/length of profemur 2.56-2.58.

Coloration. Head, abdomen, legs light brown; thorax with light brown ground with brownish black postnotum and preepisternum.

Head. Antenna with 13 flagellomeres. Terminal flagellomere length 115-153 $\mu \mathrm{m}$, conspicuous swollen apically and with strong sensory setae. AR 0.26-0.48. Temporal setae 5-9, including 2-4 inner verticals, 3-5 outer verticals. Clypeus with 7-10 setae. Tentorium 72-84 $\mu \mathrm{m}$ long, $14-19 \mu \mathrm{m}$ wide. Palpomere lengths (in $\mu \mathrm{m}$ ): $22-24$; $24-26 ; 48-55 ; 60-65 ; 91-96$. L: $5^{\text {th }} / 3^{\text {rd }} 1.62-1.65$.

Wing (Figure 24). VR 1.15-1.27. Anal lobe obtuse. Brachiolum with 1 seta; $\mathrm{R}$ with 4 setae; $\mathrm{R}_{4+5}$ with $0-1$ seta; other veins bare. Squama with $0-1$ seta. Costa extension $60 \mu \mathrm{m}$ long. $\mathrm{Cu}_{1}$ slightly curved.

Thorax (Figure 25). Antepronotum with 4-6 lateral setae, dorsocentrals 6-9, acrostichals $0-1$, prealars $4-6$. Scutellum with 6-7 setae. 

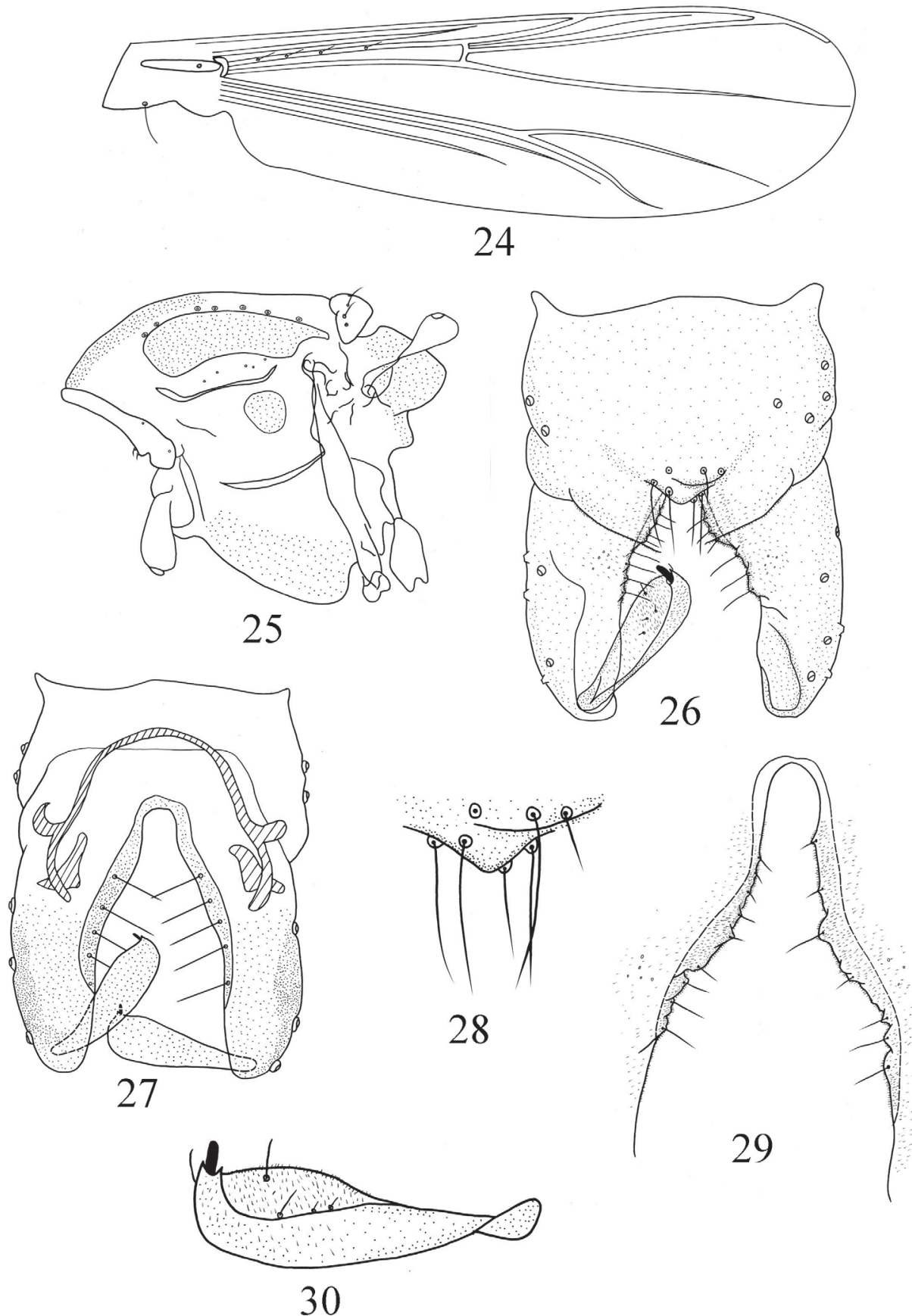

Figures 24-30. Pseudorthocladius (P.) paucus sp. n., male. 24 wing $\mathbf{2 5}$ thorax $\mathbf{2 6}$ hypopygium (dorsal view) $\mathbf{2 7}$ hypopygium (ventral view) $\mathbf{2 8}$ anal point $\mathbf{2 9}$ inferior volsella $\mathbf{3 0}$ gonostylus. 
Table I0. Lengths (in $\mu \mathrm{m}$ ) and proportions of legs of Pseudorthocladius (P.) paucus sp. n.

\begin{tabular}{c|c|c|c}
\hline & $\mathbf{p}_{\mathbf{1}}$ & $\mathbf{p}_{\mathbf{2}}$ & $\mathbf{p}_{\mathbf{3}}$ \\
\hline $\mathrm{fe}$ & $320-360$ & $320-380$ & $430-490$ \\
\hline $\mathrm{ti}$ & $340-360$ & $350-380$ & $370-410$ \\
\hline $\mathrm{ta}_{1}$ & $210-250$ & $140-150$ & $200-230$ \\
\hline $\mathrm{ta}_{2}$ & $130-160$ & $72-77$ & $108-120$ \\
\hline $\mathrm{ta}_{3}$ & $108-130$ & $55-62$ & $91-96$ \\
\hline $\mathrm{ta}_{4}$ & $64-67$ & $36-40$ & $41-46$ \\
\hline $\mathrm{ta}_{5}$ & $52-55$ & $41-43$ & $41-48$ \\
\hline $\mathrm{LR}$ & $0.62-0.69$ & $0.35-0.40$ & $0.52-0.56$ \\
\hline $\mathrm{BV}$ & $2.27-2.36$ & $3.88-4.17$ & $3.10-3.54$ \\
\hline $\mathrm{SV}$ & $2.88-3.19$ & $4.79-5.07$ & $3.44-3.65$ \\
\hline $\mathrm{BR}$ & $2.20-2.50$ & $3.20-3.40$ & $3.57-4.00$ \\
\hline
\end{tabular}

Legs. Pulvilli present. Spur of fore tibia 29-34 $\mu \mathrm{m}$ long, spurs of mid tibia both 17-19 $\mu \mathrm{m}$ long; hind tibia with a long spur 31-33 $\mu \mathrm{m}$ long, a short spur 19-24 $\mu \mathrm{m}$ long and comb composed of 10-12, 11 spines. Width at apex of fore tibia 21-26 $\mu \mathrm{m}$, of mid tibia 21-24 $\mu \mathrm{m}$, of hind tibia 24-29 $\mu \mathrm{m}$. Lengths (in $\mu \mathrm{m}$ ) and proportions of legs as in Table 10.

Hypopygium (Figures 26-30). Laterosternite IX with 3-4 setae. Anal point (Figure 28) subtriangular with round apex, 9-10 $\mu \mathrm{m}$ long and 24-26 $\mu \mathrm{m}$ wide, with 4-5 lateral setae and 2-5 long setae around the base. Phallapodeme 22-24 $\mu \mathrm{m}$ long. Transverse sternapodeme 43-48 $\mu \mathrm{m}$ long. Virga absent. Gonocoxite 77-89 $\mu \mathrm{m}$ long with reduced parallelsided inferior volsella (Figure 29). Gonostylus (Figure 30) 43-50 $\mu \mathrm{m}$ long, expanded at the apex, crista dorsalis reduced. Megaseta $5 \mu \mathrm{m}$ long. HR 1.60-1.83. HV 2.90-3.25.

Female, pupa and larva unknown.

Type materials. Holotype: $\widehat{\partial}$ (BDN No.25207), China, Hunan, Hengyang County, Heng Mountain, $27^{\circ} 15^{\prime} \mathrm{N}, 112^{\circ} 51^{\prime} \mathrm{E}, 19 . v i i .2004$, Chuncai Yan, sweep net.

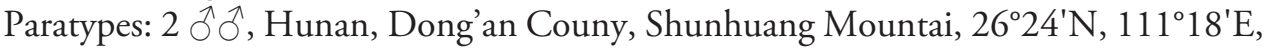
26.vii.2004, Chuncai Yan, sweep net.

Etymology. The specific name is from Latin, paucus, meaning "few", referring to the new species has few setae on squama, $\mathrm{R}_{4+5}$ and acrostichals.

Remarks. The new species resembles $P$. ( $P$.) oyabecrassus Sasa, Kawai \& Ueno, 1988 in the low AR $(0.43,0.50)$, gonostylus strongly expanded at about distal, but can be separated from $P$. (P.) oyabecrassus on the basis of characters in table 11.

Distribution. The new species is known from Hunan Province in Oriental China.

Table I I. Main different characters between $P$. (P.) paucus sp. n. and $P$. (P.) oyabecrassus Sasa, Kawai \& Ueno (1988).

\begin{tabular}{c|c|c}
\hline & $\boldsymbol{P}(\boldsymbol{P})$ paucus sp. $\mathbf{n}$. & $\boldsymbol{P}(\boldsymbol{P})$ oyabecrassus Sasa, Kawai \& Ueno \\
\hline Body length & $1.49-1.60 \mathrm{~mm}$ & $2.18 \mathrm{~mm}$ \\
\hline Acrostichals & $0-1$ & 11 \\
\hline Anal point & subtriangular with round apex & conical, darkly pigment \\
\hline Pulvilli & present & absent \\
\hline Inferior volsella & parallel-sided & with a small projection \\
\hline
\end{tabular}


Pseudorthocladius (Pseudorthocladius) uniserratus Sæther \& Sublette, 1983 http://species-id.net/wiki/Pseudorthocladius_uniserratus

Pseudorthocladius (Pseudorthocladius) uniserratus Sæther \& Sublette, 1983: 71; Ashe and O'Connor 2012: 538.

Diagnosis. AR 0.63-0.95; $\mathrm{R}$ with 3-13 setae, $\mathrm{R}_{1}$ with $0-6$ setae, $\mathrm{R}_{4+5}$ with $0-13$ setae; squama with 4-6 setae; inferior volsella trianguler at middle; virga consisting of very weak field of about 20 minute spinules; crista dorsalis low, HR 1.68-1.91, HV 2.53.

Specimens examined. China: Hunan Province: $1 \hat{\jmath}$, Chenzhou City, Yizhang

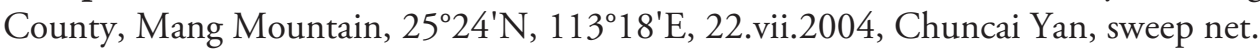

Remarks. Sæther and Sublette (1983) described the male imago, pupa and larva from the U.S.A. The Chinese specimens mainly agree with the adult description of Sxther and Sublette (1983). According to Sxther and Sublette (1983), there are not significant differences between $P$. (P.) uniserratus and $P$. (P.) curtistylus in the male hypopygium, but as we can see in the figures of $P$. $(P$.) uniserratus, the gonostylus is expanded at about distal while $P$. $(P$.) curtistylus is narrowed; the inferior volsella is triangler at middle part. The Chinese specimens agree with $P$. (P.) uniserratus more.

Distribution. Oriental China (Hunan Province); U.S.A.; Canada.

\section{Pseudorthocladius (Lordella) wingoi Sæther \& Sublette, 1983}

http://species-id.net/wiki/Pseudorthocladius_wingoi

Pseudorthocladius (Lordella) wingoi Sxther \& Sublette, 1983: 98; Ashe and O'Connor 2012: 530.

Pseudorthocladius (Lordella) comans Sæther \& Sublette, 1983: 95; Cranston and Oliver 1988: 446.

Diagnosis. Inferior volsella hook-liked, bended posteriad; gonostylus broadest at base and densely covered with microtrichia; virga with 5-8 stronger spines and 0-20 finer spinules; AR 0.8-1.1; dorsocentrals 10-16; R with 1-3 setae, exceptionally with 12 setae.

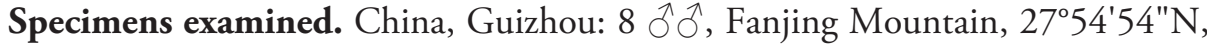
10841'42"E, 28.v.-3.vi.2002, Bingchun Ji, sweep net.

Remarks. The Chinese specimens mainly agree with the description by Sæther and Sublette (1983). According to Cranston and Oliver (1988), P. (L.) comans is a synonym of $P$. $(L$.) wingoi. Based on the specimens from Canada the shape of the gonostylus is highly dependent on orientation and the spines might be correlated with size, so $P$. (L.) comans and $P$. (L.) wingoi should be the same species. The minor differences between Chinese specimens and North America specimens are as follows: (1) The anal point is a little shorter $(12-17 \mu \mathrm{m})$; (2) with small AR $(0.75-0.86)$; (3) dorsocentrals 7-8.

Distribution. Oriental China (Guizhou Province); U.S.A.; Canada. 


\section{Key to males of the genus Pseudorthocladius from China}

1 Inferior volsella hook-liked, curved posteriad; gonostylus broadest at base and densely covered with microtrichia.....P. (Lordella) wingoi Sæther \& Sublette Inferior volsella rounded, or bluntly triangular, never hook-shaped; gonostylus widest some distance from base or at apex, with less conspicuous microtrichia P. subg. Pseudorthocladius Wing membrane densely covered with setae. $P$. (P.) cristagus Stur \& Sæther Wing membrane bare 3 Gonostylus with median sharp bend and tapering apex

P. (P.) morsei Sæther \& Sublette

Inferior volsella finger-shaped ....................................................... Squama with 8 setae, inferior volsella with about 6 stout setae, transverse sternapodeme without oral projection. P. (P.) jintutridecima (Sasa)

- $\quad$ Squama bare, inferior volsella with few weak setae, transverse sternapodeme with oral projection

$P$. (P.) digitus sp.n. Virga consisting of 2 broader lateral spines and 4 partially fused median spines $P$. (P.) macrovirgatus Sæther \& Sublette AR $0.26-0.48$, acrostichal $0-1$, R with 4 setae, dorsocentrals $6-9$

P. (P.) paucus sp.n.

$\mathrm{AR} \leq 0.64$ or $\geq 1.31$, acrostichals $8-14$, $\mathrm{R}$ with $10-13$ setae, dorsocentrals $12-25$. AR 1.31-1.55, squama 14-18, dorsocentrals 20-25, anal point rounded..... $P$. (P.) ovatus sp.n. AR 0.45-0.64, squama 3-4, dorsocentrals 12-18, anal point triangular ... 11 AR $0.45-0.51$, crista dorsalis rounded and protruding.....

P. (P.) curtistylus (Goetghebuer)

AR $0.63-0.81$, crista dorsalis lower and less rounded

P. (P.) uniserratus Sæther \& Sublette

\section{Acknowledgements}

Financial support from the National Natural Science Foundation of China (NSFC, grant No. 30870329; 31272284; 31301908; J1210005), Fauna of China (FY120100) and SinoFrench Haihe IWRM Project (grant No. 2013DFA71340) are acknowledged with thanks. 


\section{Reference}

Ashe P, O'Connor JP (2012) A world catalogue of Chironomidae (Diptera). Part 2. Orthocladiinae. Irish Biogeographical Society, National Museum of Ireland, Dublin, 968 pp.

Brundin L (1956) Zur Systematik der Orthocladiinae (Dipt., Chironomidae). Report from the Institute of Freshwater Research, Drottningholm 37: 5-185.

Coe RL (1950) Family Chironomidae. Handbooks for the Identification of British Insects 9: 121-206.

Cranston PS, Oliver DR (1988) Additions and corrections to the Nearctic Orthocladiinae (Diptera: Chironomidae). Canadian Entomologist 120: 425-462. doi: 10.4039/Ent120425-5

Cranston PS, Oliver DR, Sæther OA (1989) The adult males of Orthocladiinae (Diptera: Chironomidae) of the Holarctic region - Keys and diagnoses. In: Wiederholm T (Ed) Chironomidae of the Holarctic region. Keys and diagnoses. Part 3 - Adult males. Entomologica Scandinavica, Supplement 34: 165-352.

Edwards FW (1929) British non-biting midges (Diptera: Chironomidae). Transactions of the Royal Entomological Society of London 77: 279-439. doi: 10.1111/j.1365-2311.1929. tb00692.x

Edwards FW (1932) Recent literature, Faune de France: 23. Diptères: Chironomidae, IV Par M. Goetghebuer. Paris (Lechevalier) 1932. The Entomologist 65: 140-141.

Goetghebuer M (1921) Chironomides de Belgique et specialement de la zone des Flanders. Memoires Du Musee Royal D’Histoire Naturelle De Belgique 8: 1-211.

Goetghebuer M (1932) Diptères(Nématocerès). Chironomidae IV. Orthocladiinae, Corynoneurinae, Clunioninae, Diamesinae. Faune de France 23: 1-204.

Goetghebuer M, Lenz F (1943) Tendipedidae (Chironomidae) Subfamilie Orthocladiinae. In: Lindner E (Ed) Die Fliegen der Palaearktischen Region 13g. Schweizerbart'sche Verlagsbuchhandlung, Stuttgart, 65-112.

Goetghebuer M, Lenz F (1940-1950) Tendipedidae (Chironomidae) Subfamilie Orthocladiinae. In: Lindner E (Ed) Die Fliegen der Palaearktischen Region 13g. Schweizerbart'sche Verlagsbuchhandlung, Stuttgart 1-208.

Laurence BR (1951) On two neglected type designations in the genus Hydrobaenus Fries, 1830. Entomologist's Monthly Magazine 86: 164-165.

Lehmann J (1971) Die Chironomiden der Fulda. Systematische, ökologische und faunistische Untersuchungen. Archiv fur Hydrobiologie Supplement 37: 466-555.

Makarchenko EA, Makarchenko MA (2012) Review of the genus Pseudorthocladius Goetghebuer, 1943 (Diptera: Chironomidae, Orthocladiinae) from the Russian Far East. Euroasian Entomological Journal 11(1): 75-82.

Pinder LCV (1978) A key to the adult males of British Chironomidae. Part 1. The key; Part 2. Illustrations of the hypopygia. Freshwater Biological Association. Scientific Publication 37: 1-169.

Sæther OA (1969) Some Nearctic Podonominae, Diamesinae and Orthocladiinae (Diptera: Chironomidae). Bulletin of the Fisheries Research Board of Canada 170: 1-154.

Sæther OA (1980) Glossary of chironomid morphology terminology (Diptera: Chironomidae). Entomologica scandinavica 14: 1-51. 
Sæther OA, Sublette JE (1983) A review of the genera Doithrix n. gen., Georthocladius Strenzke, Parachaetocladius Walker, and Pseudorthocladius Goetghebuer (Diptera: Chironomidae, Orthocladiinae). Entomologica Scandinavica Supplement, 100 pp.

Sæther OA, Ashe P, Murray DE (2000) Family Chironomidae. In: Contributions to a Manual of Palaearctic Diptera (with special reference to the flies of economic importance). Vol. 4. Appendix A.6. Science Herald, Budapest 113-334.

Sasa M, Kawai K (1987) Studies on chironomid midges of Lake Biwa (Diptera, Chironomidae). Lake Biwa Research Institute, Otsu 3: 1-119.

Sasa M, Kawai K, Ueno R (1988) Studies on the chironomid midges of the Oyabe River, Toyama, Japan. In: Some characteristics of Nature Conservation within the chief rivers in Toyama Prefecture (The upper reach of Oyabe River), Toyama Prefectural Environmental Pollution Research Cente, 26-85.

Sasa M (1996) Studies on chironomids additionally collected on the shore of Jinzu River, Toyama. In: Some characteristics of water quality and aquatic organism in the chief lakes of Toyama Prefecture (Konadegawa Reservoir), Toyama Prefectural Environmental Pollution Research Center, 16-112.

Sasa M, Suzuki H (1999) Studies on the chironomid midges of Tsushima and Iki Islands, western Japan. Part 2. Species of Orthocladiinae and Tanypodinae collected on Tsushima. Tropical Medicine 41: 75-132.

Sasa M, Suzuki H (2000) Studies on the chironomid midges collected on Yakushima Island, Southwestern Japan. Tropical Medicine 42: 53-134.

Schnell ØA (1991) New records of Chironomidae (Diptera) from Norway (II), with two new species synonyms. Fauna Norvegica Serie B 38: 5-10.

Strenzke K (1950) Systematik, Morphologie und Okologie der terrestrischen Chironomiden. Archiv fur Hydrobiologie, Supplement 18: 209-414.

Stur E, Sæther OA (2004) A new hairy-winged Pseudorthocladius (Diptera: Chironomidae) from Luxembourg. Aquatic Insects 26: 79-83. doi: 10.1080/01650420412331325819

Thienemann A, Krüger F (1939) Terrestrische Chironomiden II. Zoologischer Anzeiger 127: 246-258.

Thienemann A (1944) Bestimmungstabellen für die bis jetzt bekannten Larven und Puppen der Orthocladiinen (Diptera, Chironomidae). Archiv für Hydrobiologie 39: 551-664.

Wang XH (2000) A revised checklist of Chironomidae from China (Diptera). In: Hoffrichter O (Ed) Late 20th Century Research on Chironomidae. An Anthology from the 13th International Symposium on Chironomidae. Shaker Verlag, Aachen 629-652.

Yamamoto M (2004) A catalog of Japanese Orthocladiinae (Diptera: Chironomidae). Acta Dipterologica 21: 1-121. 